\title{
Uma Iniciativa de Formação Docente em Design Instrucional sob os enfoques de Design Thinking e Experiência do Usuário
}

\author{
César A. R. Bastos, Sean W. M. Siqueira \\ Programa de Pós-Graduação em Informática - Universidade Federal do Estado do Rio de \\ Janeiro (UNIRIO) - Rio de Janeiro - RJ - Brasil \\ \{cesar.bastos@uniriotec.br, sean@uniriotec.br\}
}

\begin{abstract}
In the classroom it is very common to hear students complaining about monotonous and outdated methodologies; teachers still reproduce in class what their teachers did decades ago. New approaches are needed to be discussed and worked on in teacher training courses. Research indicates that the Design Thinking (DT) approach and the focus on User eXperience (UX) can contribute to achieving good results considering products, users and context, and possibly with teachers and students. Thus, this article presents an initiative for the training of distance education teachers / tutors in Instructional Design (ID), using DT and UX. The course reports show, in general, a positive result of the study, explaining a quality gain in rethinking ID planning, which may lead to the development of new technologies that support the process.
\end{abstract}

\begin{abstract}
Resumo Nas salas de aula é muito comum ouvir alunos reclamando de aulas monótonas e com metodologias ultrapassadas; professores ainda reproduzem em sala o que seus professores fizeram décadas atrás. Novas abordagens se fazem necessárias serem discutidas e trabalhadas em cursos de formação de professores. Pesquisas sinalizam que a abordagem de Design Thinking (DT) e o foco na Experiência do Usuário (UX) podem contribuir para que bons resultados sejam alcançados considerando produtos, usuários e contexto, e possivelmente com professores e alunos. Desta forma, apresenta-se neste artigo uma iniciativa de formação de professores/tutores de EaD (Educação a Distância) em Design Instrucional (DI), usando DT e UX. Os relatos dos cursistas mostram, de um modo geral, um resultado positivo do estudo explicitando um ganho de qualidade no repensar o planejamento de DI, o que pode levar ao desenvolvimento de novas tecnologias que apoiem o processo.
\end{abstract}

\section{Introdução}

Parte dos professores desta década foi formada com base em práticas pedagógicas do século passado e não utilizaram tecnologias que os alunos utilizam hoje em sua formação: tablets, smartphones, computadores. Assim, é comum professores realizarem o planejamento de aulas com base em suas próprias experiências, sem o suporte de modelos pedagógicos (Oliveira et al, 2017). Por outro lado, os alunos cada vez mais vivem uma cultura digital, fazem uso de mundos virtuais, simuladores, redes sociais e internet no cotidiano e na sala de aula, tornando importante que o professor domine a tecnologia para melhor entender os processos de 
VIII Congresso Brasileiro de Informática na Educação (CBIE 2019)

Anais do XXV Workshop de Informática na Escola (WIE 2019)

construção de conhecimento de seus alunos e adotar estratégias que promovam a criatividade e a criticidade (Ribeiro, 2011).

Observa-se, assim, a importância de uma atualização contínua dos professores para incluírem esta nova realidade dos alunos, esta cultura digital em suas práticas docentes, de modo a trazer suas aulas para o dia-a-dia dos alunos, promovendo a identificação dos mesmos com as aulas (Silva, 2005). Diante deste cenário parece fundamental para a compreensão desta realidade da Cibercultura com a prática docente um repensar no planejamento de aulas e o Design Instrucional (DI) pode contribuir para estas ações explorando o potencial de ferramentas computacionais (Garrido, 2018). DI, definido pela Association for Educational Communications and Technology (AECT) como a teoria e prática de design, é utilizado para um melhor aproveitamento dos recursos educacionais disponíveis para a educação. É um processo iterativo para o planejamento de aulas, seleção de estratégias instrucionais, escolha de recursos digitais, de objetivos de desempenho e avaliação. É a ciência da criação de currículo de instrução para produção de resultados de aprendizagem específicos, com base em pesquisa pedagógica e práticas de instrução contemporâneas (Filatro 2008).

Um dos modelos de DI mais utilizados em cursos online é o ADDIE (Analysis, Design, Development, Implementation e Evaluation), criado por Clark (2014), com fases bem definidas que podem ser adaptadas às características de cada curso, professor e estudante. $\mathrm{O}$ DI é tradicionalmente utilizado em cursos online para facilitar a construção de conhecimentos e competências (Falcad, 2016). Um repensar no planejamento de aulas pode ser realizado através de novas abordagens, como o enfoque de Design Thinking e Experiência do Usuário.

O Design Thinking (DT) é uma nova abordagem que abraça todo o processo de inovação, desde a geração de ideias à inserção de mercado, com uma característica otimista, construtiva e experimental, com foco em solução de necessidades dos consumidores com relação a produtos e/ou serviços, considerando também sua arquitetura (Bonini et al, 2012). A abordagem de DT aponta direções inovadoras focadas nas pessoas e vem se popularizando com bons resultados em empresas de diversas áreas de atuação como uma nova forma de pensar e abordar problemas. A IDEO apresenta DT para o contexto de Educação ${ }^{1}$ como um modelo de pensamento focado nas pessoas e de inovação, e o seu processo é representado em cinco fases (figura 1):
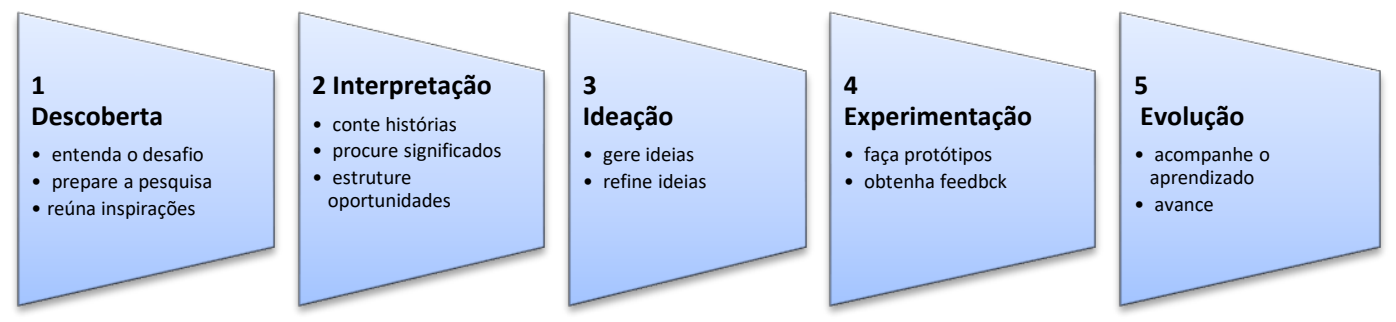

Figura 1 - Fases do Processo de DT, adaptado de "Design Thinking para Educadores".

\footnotetext{
${ }^{1}$ Design Thinking for Educators - "http://www.dtparaeducadores.org.br/site/material/"
} 
VIII Congresso Brasileiro de Informática na Educação (CBIE 2019)

Anais do XXV Workshop de Informática na Escola (WIE 2019)

Para entender a experiência e contexto do usuário é importante se colocar no lugar do outro e também observar o contexto de trabalho no qual o usuário está inserido e todos os aspectos relacionados (Demilis, 2015). A experiência do usuário, User eXperience - UX (Norman, 2004), é tudo o que está relacionado com a experiência do usuário com o produto, incluindo o que pode ser falado sobre ele para alguém. A UX auxilia na definição geral de um produto, da forma, do comportamento e do conteúdo, assegurando a coerência e consistência em todas as dimensões de projeto. Novas formas de interação entre produtos e a sociedade podem ser desenvolvidas com a integração de usabilidade e UX (Araújo, 2014). Assim, UX procura integrar à experiência emocional a funcionalidade e a técnica que um cliente tem ao consumir um serviço ou produto. Para ser menos subjetiva, a UX pode ser delimitada para produtos ou serviços através de uma interface de usuário onde ocorrem as interações com o usuário (Law et al, 2009). O bloco de informações Produto-serviço, Usuário e Contexto constituem a Experiência (Merino, 2014).

Embora esta definição de UX possa parecer distante do contexto educacional, um exemplo desse bloco no contexto de educação é o caso de alunos que aprendem a construir robôs na escola e concluem sua experiência vivenciando as competições e eventos de robótica. Nesse cenário o produto-serviço é o robô, o usuário é o aluno desenvolvendo o robô, o contexto é um laboratório de robótica. Então o aluno desenvolve robôs para competição em um laboratório de robótica, com um grupo de alunos e ajuda de um professor. A experiência completa envolve não apenas o desenvolvimento do produto (robô), mas a participação do usuário (aluno) em um contexto (competições e eventos de robótica), pois esta experiência traz a motivação para o aprendizado de robótica.

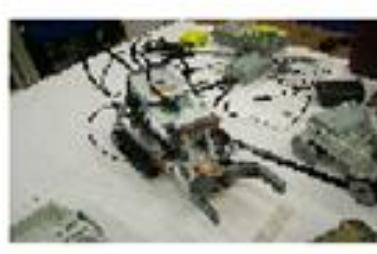

Produto-serviço

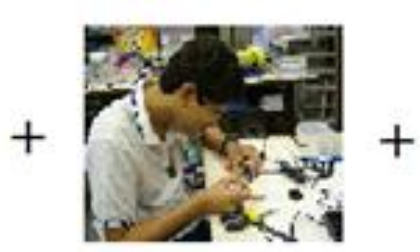

Usuário

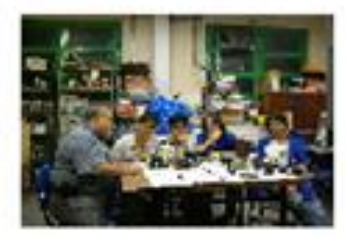

Contexto

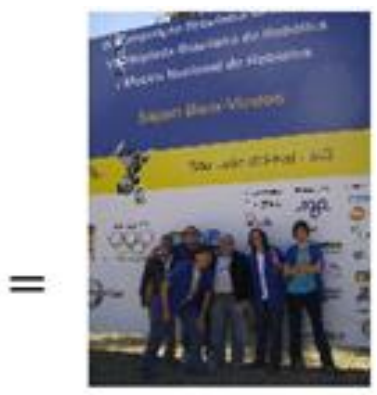

Experiência

Figura 2 - Bloco de informações, adaptado de (Merino e Merino, 2014).

Será que repensar o planejamento de aulas agregando as contribuições DT e UX no Design Instrucional pode contribuir para uma melhor compreensão das necessidades e desejos do usuário em seu contexto? Para investigar essa abordagem e como os professores se sentem integrando DT, UX no DI fez-se um estudo com uma disciplina em EAD com uma atividade para a disciplina "A importância do DI em cursos online" para cursistas da Extensão do CEDERJ $^{2}$ e neste artigo são apresentados a experiência e os resultados. Assim, este artigo apresenta as características de DI, abordagens de DT e UX, a análise de um estudo de pesquisa-formação, usando princípios das abordagens de DT e UX em um curso de formação

\footnotetext{
${ }^{2}$ Fundação CEDERJ - Extensão: http://cederj.edu.br/extensao/
} 
VIII Congresso Brasileiro de Informática na Educação (CBIE 2019)

Anais do XXV Workshop de Informática na Escola (WIE 2019)

de professores/tutores de Educação a Distância $(\mathrm{EaD})$, os resultados obtidos e trabalhos correlatos.

\section{Trabalhos relacionados}

Inicialmente pesquisou-se nas bases Google Scholar e nas publicações do Simpósio Brasileiro de Informática na Educação - SBIE utilizando as variáveis "design thinking" "instructional design" "user experience", em língua inglesa, e encontrou-se 565 resultados. Considerando o cenário de experiências em contextos nacionais optou-se por um filtro com língua portuguesa e encontrou-se 9 resultados. Dos resultados encontrados, os que estão mais relacionados ao descrito neste artigo são apresentados nesta seção.

Athayde et al. (2017) utilizam Design Thinking e estratégias de gamificação para tornar a aula mais agradável, condizente com a expectativa dos alunos. A experiência do usuário nesta pesquisa não foi utilizada para integrar à experiência emocional a funcionalidade e a técnica que os alunos têm ao utilizar um jogo ou aula online, não se preocupando com o bloco de informações Produto-serviço, Usuário e Contexto como no presente estudo.

Garreta et al. (2018) defendem que para melhorar e inovar a educação é necessária uma nova concepção do papel do design na educação. Traduzem essa concepção no contexto da aprendizagem avançada por tecnologia, abordando tanto o design da aprendizagem, em particular as atividades de aprendizagem, quanto o design da tecnologia educacional. Se concentram no design centrado no ser humano (HCD), uma estrutura de solução de problemas sustentada pelo envolvimento do usuário em todas as etapas do processo. O HCD fornece aos designers profissionais uma mentalidade e uma caixa de ferramentas que inclui processos e métodos. É multidisciplinar por padrão e também orientado para a prática, sensível ao contexto, empático e incremental. Essa proposta se concentra em como o HCD pode melhorar e facilitar a aprendizagem aprimorada pela tecnologia (1) concentrando-se na concepção de atividades de aprendizagem, (2) envolvendo todos os seus atores de maneira oportuna e significativa; e (3) afetando seus níveis micro, meso e macro. Contudo esta concepção exige uma experiência avançada com tecnologia educacional.

Alves (2015) investiga de que maneira os elementos de design de jogos situam-se como instrumentos mediadores entre os usuários e o DI em ambientes virtuais de aprendizagem (AVA). A partir de uma abordagem participativa do DI em AVA utilizou o método de codesign e medalhas no desenvolvimento do DI. Considerou a experiência do usuário no planejamento de atividades gamificadas, contudo essa experiência foi desenvolvida com base no modelo ADDIE tradicional em DI o que diferencia da abordagem inovadora utilizada neste estudo, que envolve DT em DI.

Tracey \& Hutchinson (2019) em seu estudo exploratório de métodos mistos, projetando objetivos e uma visão do futuro, investigaram como os designers instrucionais imaginaram a experiência cognitiva e emocional do aprendiz ao projetarem um estudo de caso interativo baseado em colaboração para promover interação e colaboração entre médicos, radiologistas e físicos de radiação. Utilizaram uma metodologia de análise de protocolo com os participantes de uma equipe de design e pesquisas on-line para documentar as trocas verbais de membros dessa equipe de projeto durante reuniões colaborativas. As pesquisas online incluíram avaliações baseadas em escala com perguntas curtas e abertas, avaliaram as percepções dos alunos sobre sua experiência instrucional. Os resultados do usuário indicam 
VIII Congresso Brasileiro de Informática na Educação (CBIE 2019)

Anais do XXV Workshop de Informática na Escola (WIE 2019)

que o resultado que os projetistas instrucionais planejaram para a experiência do usuário foi alinhado com as percepções do usuário sobre suas experiências durante a atividade. Mesmo investigando com UX, nesta pesquisa não foram utilizados princípios da abordagem de DT, o que diferencia da abordagem inovadora utilizada neste estudo.

Matthews \& Yanchar (2018) realizaram um estudo qualitativo da tensão entre abordagens manipulativas e cooperativas para o design instrucional e verificaram que os participantes lutaram para resistir a tendências manipulativas em seus contextos de trabalho. Os dados indicaram que os participantes procuraram projetar com seus alunos para promover uma abordagem mais cooperativa. Os participantes deste estudo relataram que fizeram perguntas-chave em sua prática de design que tinham a ver com: 1 - convidar os alunos a se envolverem através de instrução relevante e significativa, 2 - imaginar o que os alunos estão pensando e sentindo, e 3 - colocar-se no lugar de seus alunos para compreender a possível experiência do aluno com a instrução projetada. Ao final recomendam, para projetistas em contextos de trabalho com restrições semelhantes, o autoquestionamento que leve a práticas cooperativas (e menos manipuladoras) de design de instrução. Neste estudo qualitativo verifica-se uma semelhança com nosso trabalho na medida em que existiu uma reação inicial dos participantes em resistir a tendências inovadoras, contudo este estudo utilizou a abordagem de DT com enfoque colaborativo.

Kane (2019) investigou em seu estudo fenomenológico descritivo como a faculdade pós-secundária experimentou oficinas de desenvolvimento instrucional emolduradas em torno dos princípios de Design Thinking. A partir da análise dos dados foram identificados quatro achados predominantes: a relação entre atividades de ritmo acelerado e seu alinhamento com a prática é uma consideração importante para promover o pensamento inovador por meio do desenvolvimento instrucional; a colaboração e comunicação entre disciplinas ajudam a facilitar o pensamento sobre a prática instrucional; a importância de incorporar maneiras de os participantes obterem feedback autêntico do aluno ao planejar o desenvolvimento instrucional centrado no aluno; a importância de alocar múltiplas oportunidades de revisão e reflexão sobre problemas e soluções identificados ao implementar o desenvolvimento instrucional baseado em problemas. Contudo esta pesquisa que se concentra em experiências do corpo docente com o Design Thinking e sugere oportunidades para implementar o desenvolvimento instrucional de pensamento de design em amplas áreas acadêmicas, não contempla UX para integrar a experiência e a técnica que o corpo docente possui e não considera o bloco de informações Produto-serviço, Usuário e Contexto como no presente estudo.

Observa-se que nenhum dos trabalhos encontrados no levantamento de literatura explora o DI com uso de DT e UX. Além disto, neste trabalho segue-se uma abordagem pesquisa-formação, partindo-se de uma análise reflexiva de docentes sobre a prática de DI tradicional e o que muda ao se considerar DT e UX, permitindo analisar as diferenças.

\section{Método Pesquisa-Formação}

Este estudo seguiu a abordagem de pesquisa-formação, realçando questionamentos e instigando possibilidades para problematizar as histórias de vida (Josso, 2004). Histórias de vida que levam professores hoje a desenvolverem suas ideias, de como dizer as coisas para que sejam compreensíveis para os alunos. A pesquisa-formação é caracterizada por contemplar a possibilidade de mudança das práticas e dos sujeitos em formação em uma 
VIII Congresso Brasileiro de Informática na Educação (CBIE 2019)

Anais do XXV Workshop de Informática na Escola (WIE 2019)

perspectiva de compromisso e de reflexão da prática, possibilitando ao pesquisador e demais sujeitos envolvidos reorientarem seu trabalho (Santos e Santos, 2015). Com essa perspectiva a coleta de dados deste estudo foi desenvolvida em um curso de formação de professores/tutores sob o título "A importância do DI em cursos online". Este curso tinha como proposta apresentar as características tradicionais de DI em cursos online e propiciar aos cursistas uma oportunidade de produzirem um minicurso utilizando DI. O curso foi estruturado em quatro etapas, no segundo semestre de 2017, para um público com perfil de professores em formação de tutores para cursos online. Na primeira etapa foram apresentadas as características de DI e o modelo ADDIE, possibilitando um entendimento de como planejar um curso seguindo uma metodologia que apoie um bom planejamento. Nesta etapa, os cursistas discutiram através de fóruns as características de cada etapa do modelo ADDIE. Na segunda etapa, cada cursista criou um minicurso considerando as discussões das etapas do modelo apresentado anteriormente. A ideia desta etapa era promover a prática e, portanto, a apropriação dos alunos em relação ao modelo. A terceira etapa foi dedicada para uma ação prática em uma plataforma de cursos online, onde cada cursista fez a implementação de seu minicurso utilizando o planejamento da etapa anterior, promovendo a apropriação do ferramental tecnológico. Após a terceira etapa, como introdução na quarta etapa, apresentouse aos cursistas as abordagens de DT e UX e as possibilidades de integração com educação. Foi recomendado o uso do material disponível no site do projeto Design Thinking para Educadores com detalhes e orientações para cada fase do processo do DT (Descoberta, Interpretação, Ideação, Experimentação e Evolução), além de textos com exemplos de aplicações de DT e UX em educação. Todas as etapas da abordagem de DT estão relacionadas com as demais e nesse contexto de educação você pode voltar e atualizar o que já foi feito com base e foco nas pessoas (alunos). A atividade seguinte pode ser repensada a partir de um resultado da atividade anterior. Portanto, o professor pode usar a abordagem DT para repensar sua sala de aula, ou curso, considerando o olhar de seus alunos, como o bloco de informações Produto-serviço, Usuário e Contexto que constituem a Experiência (Merino, 2014).

Deste modo, como última atividade do curso, ainda na quarta etapa, foi proposto como tarefa que cada cursista repensasse o DI de seu minicurso, planejado e implementado nas etapas anteriores, agora com foco nos alunos considerando DT e UX. Essa atividade é uma ideação de acordo com as fases de DT. A atividade proposta sugere que os cursistas reflitam e refinem suas ideias no minicurso se colocando no lugar do aluno e considerando o contexto do aluno.

Nesta proposta foi contemplada a possibilidade de mudança das práticas e dos sujeitos em formação em uma perspectiva de compromisso e de reflexão da prática, possibilitando a cada cursista reorientar seu trabalho inovando-o com novas abordagens. Observa-se que os minicursos haviam sido criados anteriormente com características tradicionais de DI, mas agora os cursistas foram levados a considerar as novas abordagens.

Como conclusão desta tarefa, foi proposto um relatório para que os cursistas pudessem descrever se houve contribuições no planejamento original do minicurso, as impressões e sentimentos sobre esse repensar no seu respectivo minicurso.

Após a conclusão da última atividade e produção dos relatórios foi feita uma análise dos dados considerando as informações importantes sobre, por exemplo, quantos cursistas consideraram que a proposta de repensar e refletir sobre sua prática considerando novas abordagens contribuiu na melhoria de seu minicurso, se de fato houve contribuição 
VIII Congresso Brasileiro de Informática na Educação (CBIE 2019)

Anais do XXV Workshop de Informática na Escola (WIE 2019)

significativa com o uso das abordagens discutidas e de acordo com a experiência dos cursistas.

\section{Resultados e discussão}

Uma análise sobre os relatórios produzidos pelos cursistas na etapa final da disciplina "A importância do DI em cursos online" mostra que os alunos consideraram uma melhoria de seu minicurso após a atividade de repensar sua prática pedagógica.

Todos os 27 cursistas, professores em formação de tutores para cursos online, concluíram a atividade e enviaram um relatório contando sobre sua caminhada, histórias e sentimentos nesse processo, aqui numerados de 1 a 27 para manter a privacidade dos autores.

O suporte pedagógico nessa disciplina foi realizado por uma tutora especialista em EAD que em muitos momentos animou a turma para a realização e organização das tarefas. $\mathrm{Na}$ última etapa alguns alunos resistiram inicialmente em repensar seu minicurso, implementado na terceira etapa, porque o julgavam estar bom e o dever cumprido na disciplina. Mas depois de concluir a quarta etapa a maioria reconheceu que o repensar de sua prática ajudou a melhorar o seu minicurso: $(1,3,5,6,7,8,9,10,11,12,13,14,15,16,17$, $18,19,20,21,22,23,24,25,26$ e 27$)$.

A maioria dos cursistas concordou que seu minicurso ficou melhor com essa atividade de repensar com foco no usuário utilizando novas abordagens com DT e UX $(1,3,6,7,8,9$, $10,11,12,13,14,15,16,17,18,19,20,21,22,23,25,26$ e 27$)$.

Um número reduzido de cursistas reconheceu que realizou poucas mudanças em seu minicurso utilizando novas abordagens, mas que o repensar fez com que atualizassem algumas tarefas e materiais de seu minicurso $(2,9,10$ e 24) e apenas uma cursista fez questão de comentar que não gostou de ter que repensar o minicurso já feito e concluído na terceira etapa do curso (4).

Analisando os relatórios dos cursistas e considerando as respectivas experiências de cada usuário na atividade de repensar o planejamento (DI), sob o ponto de vista do aluno, foi possível tabular as experiências considerando o nível de mudanças realizadas em três categorias: mudanças significativas, poucas mudanças significativas ou não fez mudanças, como indica a tabela 3 .

tabela 3: nível de mudanças

\begin{tabular}{|l|l|l|}
\hline Tipos de mudanças & \multicolumn{1}{l|}{ Total } & \multicolumn{1}{l|}{} \\
\hline Não fez modificações & 1 & $3,7 \%$ \\
\hline Poucas mudanças significativas & 8 & $29,6 \%$ \\
\hline Mudanças significativas & 17 & $63,0 \%$ \\
\hline
\end{tabular}

"Poucas mudanças significativas" representa que o repensar da prática provocou poucas alterações no material produzido, nos tipos de atividades e estrutura do DI do minicurso considerando as abordagens de DT e UX apresentadas após a implementação do minicurso. Os que sinalizaram que houve "mudanças significativas" em seu minicurso indicaram que estudar as abordagens de DT e UX, apresentadas após a implementação do 
VIII Congresso Brasileiro de Informática na Educação (CBIE 2019)

Anais do XXV Workshop de Informática na Escola (WIE 2019)

minicurso, contribuiu significativamente para atualizar o material produzido sob características tradicionais de DI. Indicaram também que o DI de seu minicurso melhorou após repensar sua prática, enriqueceram com novas atividades e/ou refizeram as atividades anteriores. Dentre as alterações comentadas no repensar os cursistas sinalizaram a contribuição do uso de ferramentas digitais ${ }^{3}$ como o Padlet e outras para criar quadros virtuais ou painéis, mudanças do tipo de atividades. Apesar de alguns cursistas não terem gostado de realizar uma atividade considerada como "refazer" o que tinha sido feito antes, a maioria se sentiu satisfeita com a nova ideação de seu minicurso produzindo alterações no DI inicial, alguns tornando o material escrito mais enxuto pensando nos seus alunos (usuários) e as avaliações considerando mais o contexto aplicado nos minicursos.

Alguns comentaram que teriam aproveitado mais se o estudo das novas abordagens fosse feito nas etapas anteriores.

As etapas do DT contribuíram na medida em que os cursistas estavam inovando e refletindo sobre o trabalho realizado, repaginando um minicurso considerando o contexto do aluno (seu usuário). Acredita-se que a diferença entre o minicurso original e o repensado pôde ser feita em um processo, procurando soluções criativas com inovação e trocas de ideias para atingir um objetivo. Durante a etapa final, em que houve o repensar do minicurso, identificouse que a etapa referente à Descoberta do DT foi praticamente herdada do minicurso anterior, uma vez que o público alvo continuou o mesmo, apesar dos cursistas sinalizarem que repensaram sobre as necessidades das pessoas que utilizariam o minicurso. Em relação à etapa de Interpretação percebeu-se nos relatórios poucas informações sobre registros e histórias, entretanto na etapa de Ideação ficou evidente as ideias novas que geraram as mudanças nos minicursos, realização de novas atividades e retiradas de algumas atividades, culminando com a Experimentação de um novo minicurso repaginado. Consequentemente a Evolução ficou evidenciada com a confirmação e satisfação da maioria de que o minicurso teve um ganho positivo.

Além de considerar UX com uma visão na experiência do aluno através do minicurso desenvolvido, nesta experiência a UX também pôde ser delimitada através da elaboração dos minicursos, interface que os cursistas utilizaram com seus usuários (alunos) procurando integrar mais funcionalidade nesse produto.

No bloco de informações Produto-serviço, Usuário e Contexto constituído nessa experiência identifica-se como os cursistas aprendem a construir minicursos e concluem sua experiência vivenciando o repensar da implementação de seu minicurso. Nesse cenário o produto-serviço é o minicurso, o usuário é o cursista desenvolvendo o seu minicurso, o contexto é um ambiente virtual de aprendizagem. Então o cursista desenvolve minicursos para seus alunos em um ambiente virtual de aprendizagem com ajuda de um tutor. A experiência completa envolve não apenas o desenvolvimento do produto (minicurso), mas a participação do usuário (cursista) considerando sua experiência em um contexto (ambiente virtual de aprendizagem), pois esta experiência traz a motivação para o desenvolvimento de cursos e práticas pedagógicas.

\footnotetext{
${ }^{3}$ A apresentação de DT na etapa 4 incluiu uma breve introdução a ferramentas digitais como estas que foram aceitas e adotadas pelos cursistas.
} 
VIII Congresso Brasileiro de Informática na Educação (CBIE 2019)

Anais do XXV Workshop de Informática na Escola (WIE 2019)

\section{Conclusão}

A abordagem de DT considera a participação das pessoas, suas histórias e contextos na imersão dos temas estudados no processo de inovação. Com uma característica otimista, construtiva e experimental essa abordagem aponta direções inovadoras focadas nas pessoas. Nesse contexto UX procura integrar à experiência emocional das pessoas a funcionalidade e a técnica que um aluno tem ao participar de uma disciplina ou projeto como ilustrado pelo bloco de informações Produto-serviço, Usuário e Contexto que constituem a Experiência. Por esta razão, considerar DT e UX no DI se mostrou um processo interessante estudado nessa pesquisa-formação, na disciplina "A importância do DI em cursos online" para professores em formação de tutores para cursos online. Repensar para construir uma experiência possibilita a identificação de falhas, criação de novas soluções e testar experiências. Os resultados das análises dos relatórios desse estudo indicam que o uso da abordagem de DT e UX no DI, considerando o contexto do aluno, trouxe contribuições no contexto acadêmico. Se o usuário, nesse caso os cursista, ficou satisfeito com o produto isso leva a crer que as alterações no processo de desenvolvimento surtiram efeito.

Apesar de essa pesquisa ter sido realizada com uma turma com apenas 27 alunos, permitiu perceber que o repensar da prática pedagógica com suporte de novas abordagens e/ou modelos pedagógicos pode contribuir para um novo olhar de DI na educação. Com base nesses dados considera-se pelo relato dos cursistas que houve um ganho de qualidade no repensar o planejamento de DI sob a experiência do usuário e o design thinking na elaboração de seu minicurso com suporte de novas abordagens e/ou modelos pedagógicos.

Como trabalho futuro, considerando a prática dessa experiência, fica a ideia de estudo em novo ciclo de investigação com um universo maior de cursistas, com perfis distintos, apresentando e discutindo DT e UX desde as etapas iniciais.

\section{Referências}

Alves, F. P. (2015). O Planejamento de Atividades Gamificadas a partir de uma abordagem participativa do Design Instrucional em ambientes virtuais de aprendizagem. Dissertação (Mestrado em Educação) - em Educação do Instituto de Educação da Universidade Federal de Mato Grosso, 2015.

Araújo, F. S. (2014). Avaliação da experiência do usuário: uma proposta de sistematização para o processo de desenvolvimento de produtos. 2014. 238 p. Tese (Doutorado) Universidade Federal de Santa Catarina, Centro Tecnológico, Programa de Pós-Graduação em Engenharia Mecânica, Florianópolis, 2014.

Athayde, L.T.; Moreira, M. R.; Aguilar, J.H. (2017). Utilização da metodologia Design Thinking e estratégias de gamificação para reinventar a experiência com EAD. In Colóquio Internacional de Design 2017. Disponível em: < http://pdf.blucher.com.br.s3-sa-east1.amazonaws.com/designproceedings/cid2017/66.pdf> Acesso em 03: julho 2019.

Bonini, L. A., Endo, G.B (2012). Design Thinking Uma Nova Abordagem da Inovação. In Biblioteca da Rede de Inovação 2012. Dispovível em: < http://www.redeinovacao.org.br/LeiturasRecomendadas/Design\%20Thinking\%20Uma\%2 0Nova\%20Abordagem\%20da\%20Inovacao.pdf>Acesso em: 04 julho 2019

Clark, D. (2014). "Por Design Instrucional Sistema e ADDIE?". Disponível em <http://goo.gl/v5V2sA> Acesso em 03: julho 2019. 
VIII Congresso Brasileiro de Informática na Educação (CBIE 2019)

Anais do XXV Workshop de Informática na Escola (WIE 2019)

Demilis, M. P. Fatores Humanos no Design de serviços: Valoração de aspectos da experiência de consumo pelo público idoso em supermercados. Florianópolis, 2015. 135 p. Dissertação (Mestrado em Design) - Programa de Pós Graduação em Design - PPGDesign, Universidade do Estado de Santa Catarina, 2015.

Falcad, A. et al (2016). Design Instrucional: um comparativo de metodologias para definição de abordagem em mundo virtual. In Anais do SBIE 2018, pages 80-89.

Filatro, A. (2008). Design Instrucional na Prática. Person Education do Brasil. 173 p.

Garreta-Domingo M., Hernández-Leo D., Sloep P.B. (2018) Education, Technology and Design: A Much Needed Interdisciplinary Collaboration. In: Kapros E., Koutsombogera M. (eds) Designing for the User Experience in Learning Systems. Human-Computer Interaction Series. Springer, Cham

Garrido, F. et al (2018). Design instrucional orientado a artefatos: uma abordagem participativa e distribuída. In Anais do SBIE 2018, pages 258-267.

Josso, M. C. (2004). Experiências de vida e formação. São Paulo: Cortez, 2004.

Kane, M. (2019). Postsecondary Faculty Experiences with Design Thinking as a Framework for Instructional Development. In Northeastern University, ProQuest Dissertations Publishing, 2019. 13812665. Disponível em: <https://repository.library.northeastern.edu/files/neu:m044cb27z> Acesso em 10 de julho 2019.

Law, Effie Lai-Chong et al . Understanding, scoping and defining user experience: a survey approach. In:Proceedings of the SIGCHI Conference on Human Factors in Computing Systems . ACM, 2009. p. 719-728.

Matthews, M.T. \& Yanchar, S.C. TechTrends (2018). "Instructional Design as Manipulation of, or Cooperation with, Learners?" in TechTrends, March 2018, Volume 62, Issue 2, pp 152-157. Disponível em: https://doi.org/10.1007/s11528-017-0245-6 Acesso em 10 de julho 2019.

Merino, G. S. A. D.; Metodologia para a prática projetual do design com base no projeto centrado no usuário e com ênfase no design universal. Florianópolis, 2014. Disponível em: https://repositorio.ufsc.br/bitstream/handle/123456789/128821/331968.pdf?sequence $=1 \&$ is Allowed=y acesso em 06/01/2018

Norman, Donald (2002). The design of everyday things. Estados Unidos: Basic Books, 2002.

Oliveira, E. W. et al (2017). Uma Análise do Processo de Planejamento de Trabalhos em Grupo no Ensino Superior. In Anais do SBIE 2017, pages 1647-1656.

Ribeiro, A.C. et al (2011). Práticas Criativas na Web 2.0: a construção de um objeto de aprendizagem. In Anais do SBIE 2011, pages 313-320.

Santos, R., Santos, E. O. (2015). Pesquisando nos Cotidianos da Cibercultura: Uma Experiência de Pesquisa-Formação Multirreferencial. In Anais do SBIE 2015, pages 69-82.

Tracey, M.W. \& Hutchinson (2019). "Empathic design: imagining the cognitive and emotional learner experience" in Association for Educational Communications and Technology 2019. Disponível em: https://doi.org/10.1007/s11423-019-09683-2. Acesso em 12 julho 2019. 